response

\section{Uncharitable Thoughts About Charity}

\section{Trudy Govier Trent University}

Many useful points are made in Ralph Johnson's "Charity Begins at Home" (ILN, June 1981). However, Johnson seems to miss significant ambiguities in Scriven's principle. To see this, consider what Johnson, following Scriven, adopts as the Principle of Charity.

The Principle of Charity which governs all levels of argument analysis is that the critic should provide the best possible interpretation of the material under consideration. (ILN, iii.3, p. 5)

Johnson quite rightly points out that this "principle" will pose problems of application in some contexts, and he notes with frustration the amount of work it seems to impose, for the critic, when stated arguments are sloppy and hasty. However, he does not dispute Scriven's ethical and prudential reasons on behalf of this critical policy; he only urges that it be restricted in its application to fully expressed arguments, from serious arguers, on serious matters. I think that this response misses some key problems with Scriven's principle.

The problem which I find in the Principle of Charity, as stated here, is in the expression "provide the best possible interpretation". This imposes on the critic the obligation to do as good a job of interpreting the discourse as he can. "Provide the best possible interpretation" could mean "interpret as well as you can"; i.e., do not miss nuances of meaning, irony, humour, sarcasm, qualifying phrases, relevance of preceding and subsequent material, and so on. (This is the sense of "best interpretation" which Johnson's students fail to supply when they take "You can no more license cats than you can license the wind" to express a serious analogy.) If the Principle of Charity is telling us to do a good job of interpreting natural discourse which may or may not express arguments, then we can scarcely dispute the principle. It is entirely unobjectionable, specifying an obligation to read or listen carefully, and get the author's meaning straight.

However, this is not the main force of the Principle of Charity as used by Scriven; nor is it its primary focus in the corollaries Johnson extracts. Scriven, telling us to "provide the best interpretation", is saying that we should "get as much force and sense as we can" out of the argument. In this sense the best possible interpretation of a natural discourse is the one which makes it express the best argument which can possibly be extracted from it. (Remember that Baum - quoted by Johnson - advised us to "add whatever premises are necessary to make the argument as good as possible." Why?) Presumably those who would have us be as strongly charitable as this would at least recommend preserving the original premises, but the advice is to make what we are analyzing into the best argument we can, by deleting extraneous irrelevant material, supplying extra premises to improve the argument, clarifying terms, and so on.

Let us refer to the Principle of Charity on the first interpretation as PC1, and to the Principle on the second, much stronger, interpretation as PC2. It is worth noting that PC2 and PC1 could be incompatible in their applications to some context. To get a good argument out of a discourse we might very well have to ignore comments which were inserted in very strong terms by the original author, and quite obviously intended to support his conclusion. Johnson's example of William French Smith's defence of himself on the discrimination issue is a case in point. What Smith said was not relevant to the issue, really, and looking at his remarks, trying to "make the best case out", leads to whitewash. "If that indeed was Smith's reasoning, then he ought to face the music - not have his false notes edited out by the critic", Johnson says. I agree.

It is important to distinguish PC1 from PC2, because the former is trivial and innocuous, while the latter is nontrivial, and contentious. By failing to distinguish these very different senses of the Principle of Charity, we may find ourselves giving PC2 the easy acceptance we owe only to PC1.

Let us briefly consider PC2. I have said that it is contentious. Why? I do not think that the purpose of studying other people's arguments is to turn these into the best possible arguments. I think that the purpose of studying other people's arguments is to discover the merits of the reasons those people have offered for their conclusion. And I think that the way to find this out is to extract premises from the natural discourse, to supply whatever missing premises are clearly warranted by the context and the actual wording of the discourse, and to try to determine whether these, taken together, provide good reasons for the conclusion. When someone looks at an argument in this way, she may decide that it contains some flaw; she has then decided that that argument, as stated by its author, fails to be cogent. That means that she has decided that the person who set forth the argument has not given her good reasons to accept the conclusion. She may accept the conclusion for different reasons, or even for no reason at all. But she studies his argument to see whether he can give some good reasons in support of the conclusion. In my view, this is what argument analysis and appraisal are for. We engage in this task in order to evaluate the rational support which has been offered for some particular claim.

There are, of course, other possible views of the purpose of argument analysis. Some may see it as oriented 
toward the discovery of the truth of the conclusion, or as having as its goal the discovery of a good case which could be made out for the conclusion. But I believe that my view of the purpose of argument analysis and appraisal is a natural, and fairly common view. And I do not believe that PC2 is a useful principle to adopt for this purpose. This is because it tends to confuse the construction of an argument (by the critic) with the appraisal (again by the critic) of someone else's argument. It is not up to the critic to figure out a good argument based on someone else's materials, by leaving out irrelevancies and inserting the most plausible supplementary premises he can possibly think of! The critic's task is to understand and evaluate what someone else has put forward as an argument. Adopting PC2 makes it all too easy to read one's own ideas into the works of other people, under the guise of "charity". One can read enough extra premises into fragmentary pre-Socratic writings to turn these into interesting arguments which would be plausible to some modern philosophical minds. Suppose we do this with, say, Heraclitus. Are we then analyzing the arguments of Heraclitus? I think not. Rather, I think that we are reconstructing Heraclitean arguments (arguments incorporating some of Heraclitus's key themes), using some original materials. We better understand thinkers of the past when we limit the amount of reading in we do, and distinguish interpretation from reconstruction. Understanding charity as PC2 leads us away from this distinction.

Between PC1 and PC2 in its thrust stands another possible Principle of Charity. This one, which I'll refer to as PC3, would urge us to endorse the more plausible of several distinct interpretations equally licensed by the actual text or discourse. If we can extract from a text several different arguments - call them $A^{*}, A^{* *}$, and $A^{* * *}$ - we should regard that text as expressing whichever of those arguments is the best. It is worth remarking here that such a principle would not give entirely determinate advice, for $A$ " may be the "best" argument in one respect, and $A^{* *}$ "best" in another. (For instance, $A^{*}$ may be inferentially perfect due to the insertion of supplementary premises; but $A^{*}$ may have problematic premises. Whereas $A^{* *}$ may be inferentially weak, because of a hasty generalization from a few premises, but be strong as far as the acceptability of its premises is concerned. This is a common situation - one which will wreak havoc, incidentally, for Johnson's proposed Principle of Discrimination, unless he imposes severe restraints on adding premises.) However, I shall ignore this problem for the moment. PC3 may well be a reasonable principle to work with, although it would require considerable clarification. However it is not as strongly charitable as PC2, due to its insistense that interpretations be licensed by the actual text. That is, in adding or deleting, one will seek a basis for one's decisions in the discourse as given, and its context. One will not delete purely on grounds of irrelevance, nor add purely on grounds of weakness, strength, or plausibility.

Perhaps the Principle of Charity which Johnson extracts from Scriven is triply ambiguous (triguous?), for it could be taken to express PC3, as well as PC1 and PC2. However, it is clear that both Johnson and Scriven work with PC2 as the primary meaning. I suggest that the Principle of Charity, in this sense, is implausibly strong in its charity. I suspect that it owes the plausibility and the wide acceptance it appears to have to its being easily confused with either PC1 or PC3. Instead of restricting the application of $\mathrm{PC} 2$ to serious contexts, as Johnson recom. mends, we could drop PC2 altogether and endorse either PC1, or PC3 (or, with suitable qualifications, both) as rules of charity. PC2 undercuts a primary purpose of argument analysis, is inefficient, leads to whitewashing of poor arguments, confuses interpretation with reconstruction, and licenses too much reading into others' material. Perhaps the best strategy for charity at home would be to dispense altogether with this kind of critical charity.

\section{note}

\section{Charity Begins Much Earlier Than Supposed}

\author{
Nicholas Griffin \\ McMaster University
}

Ralph Johnson in his article "Charity Begins at Home" (/LN, iii.3) says that the first use of the term 'principle of charity' of which he is aware is Stephen Thomas's Practical Reasoning in Natural Language (1973). In fact the term has been around for considerably longer than that. To the best of $m y$ knowledge, it was introduced by Neil Wilson, "Substances without Substrata", Review of Metaphysics, 12 (1959) in pp. 521-39. In this version it was a rule for translators:

We select as designatum that individual which will make the largest possible number of ... statements true. (p. 532).

The principle has seen considerable use land alteration) since then. But, apart from acknowledgements by Quine (Word and Object, [Cambridge, Mass.: M.I.T. Press, 1960], p. 59n; Ontological Relativity [New York: Columbia University Press, 1969], p. 46n) its provenance has not been widely recognized. 